\title{
The Necessity and Complexity of Standardization
}

T.V. KAZANTSEVA
Institute of New
Materials and
Technologies
Ural Federal
University named after
the first President of
Russia B.N. Yeltsin
19 Mira str.,
Ekaterinburg
RUSSIA

\author{
N.K. KAZANTSEVA \\ Institute of New \\ Materials and \\ Technologies \\ Ural Federal \\ University named after \\ the first President of \\ Russia B.N. Yeltsin \\ 19 Mira str., \\ Ekaterinburg \\ RUSSIA
}

\author{
G.A. TKACHUK \\ Institute of New \\ Materials and \\ Technologies \\ Ural Federal \\ University named after \\ the first President of \\ Russia B.N. Yeltsin \\ 19 Mira str., \\ Ekaterinburg \\ RUSSIA
}

\section{A.L. NEVOLINA Institute of New Materials and Technologies Ural Federal \\ University named after the first President of Russia B.N. Yeltsin \\ 19 Mira str., Ekaterinburg RUSSIA}

\author{
V.S. KUKHAR \\ Department of Metal \\ Technology and Machine \\ Repair \\ Ural State Agrarian \\ University \\ 42 Karla Libknekhta str., \\ Ekaterinburg \\ RUSSIA
}

$\begin{array}{cc}\text { N.A. BAGANOV } & \text { V.A. ALEKSANDROV } \\ \text { Department of Machines and } & \text { Department of Metal } \\ \text { Technologies of AIC } & \text { Technology and Machine } \\ \text { Stavropol State Agrarian } & \text { Repair } \\ \text { University } & \text { Ural State Agrarian } \\ \text { Zootechnical lane, 12, } & \text { University } \\ \text { Stavropol } & \text { 42 Karla Libknekhta str., } \\ \text { RUSSIA } & \text { Ekaterinburg } \\ & \text { RUSSIA }\end{array}$

Abstract: - The standards are one of the most important infrastructural elements of the economy. The relationship between all factors ensuring product quality and safety is carried out by using complex standardization. The standards establish and ensure the technically achievable level of safety, quality and competitiveness of products. The main factors of standardization object: the object composition, object production and monitoring, in their turn, form the following more precise groups of factors, determining the object quality: primary products and materials, component nodes and parts, production technology, equipment, tools and appliances, measurement means, and test methods.

On the example of a specific standard, the "tree of references" of the first and second levels and the problems of an integrated approach for establishing quality requirements for a specific product is considered. The necessity and complexity of updating the requirements that ensure the systematization, optimization and coordination of all interacting factors influencing a specific object of standardization and providing an economically optimal level of quality of the object are demonstrated.

Key-Words: - complex standardization, standard, interconnection of the requirements, coordination of the requirements, regulatory references.

Received: May 15, 2020. Revised: August 27, 2020. Accepted: September 14, 2020. Published: October 23, 2020.

\section{Introduction}

In the contemporary conditions of digital economy establishment, the efficient market extension and branch evolution are possible only in presence of developed platforms, technologies, institution and infrastructure environments [1]- [4]. The digital economy is based on creation of global information systems, which are designated for storage of, searching for, and processing of information of various types, that is why all useful information shall comply with new handling conditions. 


\section{The relevance and significance of the research}

The national framework of standards of the Russian Federation contains about 37000 standards and represents highly valuable information, which has been selected and time proven, improved and combined [5]-[7]. The standards fulfil economic, informational, social, communicative, resourcesaving and a number of other functions, and that is why they are one of the most important infrastructure elements of economy [8]-[11]. The forming-up and development of digital economy is possible only on the basis of developing and improving standards. Currently, the number of standards is increasing, and they are able to work effectively only in the case of a direct connection with information and communication technologies [12]. It is necessary to assess the composition of the standards by the date of their adoption and the sphere of influence, assess the level of mutual references of standards to predict the possibility of embedding the requirements of standards in information and communication technologies. Such analysis became the purpose of this study.

\section{Research design}

Nowadays, the most important performance of work in the area of standardization are the terms of new standard adoption and terms of regulatory document validity. The extent of the activities, required in the area of standardization by this criterion, may be assessed at the example of dynamics of adopting standards for pipe products. At the same time, standards for pipe products of Germany, China and international standards ISO are known and widely used in Russia [13], [14].

In Fig. 1 the number of applied national standards of Russia, Germany, China and international standards, is represented in accordance with the dates of their adoption.

It is obvious for all considered levels of standard adoption, that the number of new standards prevails, and the standard framework is considerably updated. In Russia, in the period from 2010 to 2019,79 new standards from 160 operating ones were adopted, and, thus, the framework of national and interstate standards is updated by approximately $50 \%$. Within the same period, 85 standards for different aspects of pipe products were adopted in the International Organization for Standardization, and the rate of updating amounts to approximately $44 \%$. Within the period from 2010 to 2019 the largest number of standards, related to the pipe products, was adopted in Germany - 117 standards, which may be found in the Russian framework Tekhexpert, in this case the rate of updating may be evaluated at the level of $60 \%$. According to the data, represented in the framework Tekhexpert, in Russia, 120 Chinese standards, related to the pipe products, are known and applied, herewith, 61 standards of 120 were adopted in the period from 2010 to 2019 , the rate of updating of this group of standards may be also evaluated at the level of $50 \%$.

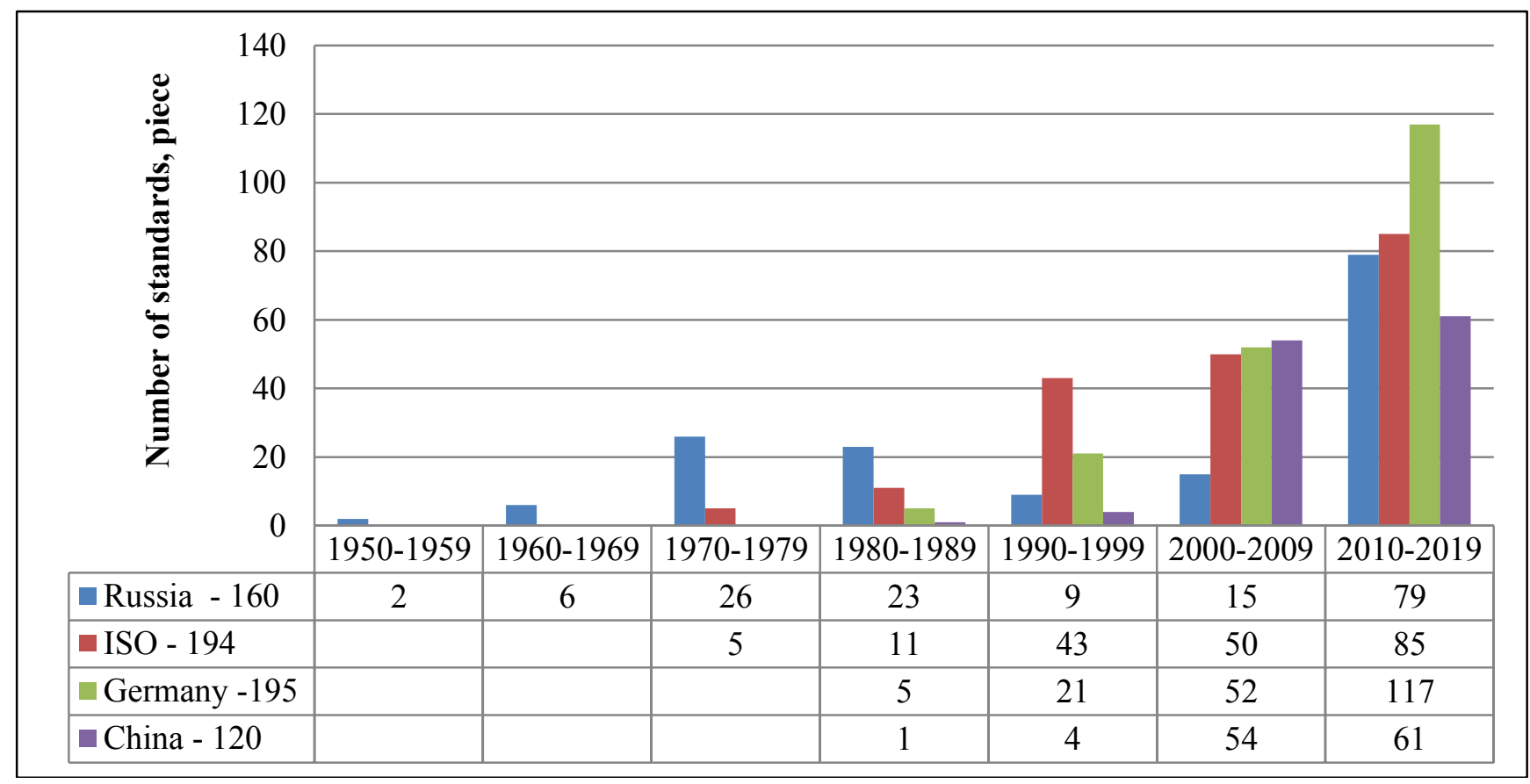

Fig. 1 The number of operating standards for pipe products applied in Russia, depending on the adoption time interval 


\section{Theoretical part}

The standards establish and ensure technically attainable level of safety, quality, and competitive ability of products. For this purpose, a special standardization method is applied - complex standardization. This is a method, in compliance with which are carried out the persistent and consistent establishment and implementation of the system of interconnected requirements to the object of complex standardization itself both in whole and to its main elements, including the substantial and nonsubstantial factors, influencing the object, being under study [15]. The essence of complex standardization comes down to the systematization, optimization and coordination of all cooperating factors, influencing the specific object of standardization and ensuring economically preferable quality level.

The empirical-theoretical methods were used to achieve the objectives of the research, namely: analysis and synthesis. The formation of standards communication models was carried out on the basis of abstraction and formalization The factors of forming of the interconnected requirements to an object may be divided into three directions: the object composition, the object production and the object quality monitoring (Fig.2).

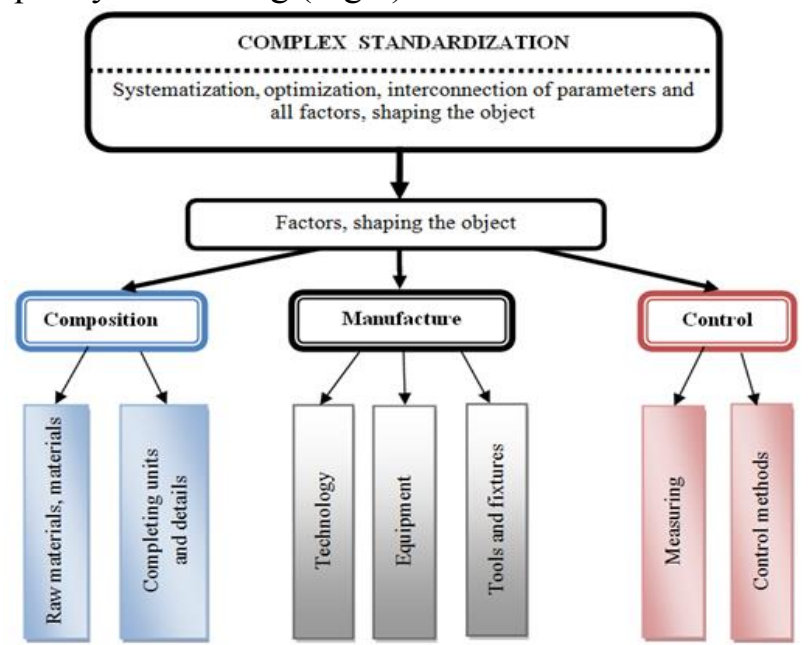

Fig. 2 Conceptual diagram of the interconnected requirements formation to standardization object.

The main factors of standardization object: the object composition, object production and monitoring, in their turn, form the following more precise groups of factors, determining the object quality: primary products and materials, component nodes and parts, production technology, equipment, tools and appliances, measurement means, and test methods.

For the purposes of pipe products high quality assurance, the intermutual consistency of the requirements under all specified directions and factor groups is required. Besides the establishment of direct regulatory provisions directly in the standard, this consistency is ensured through regulatory references, specified in the considered standard for the products. Thus, the complex standardization ensures the forming-up of consistent requirements both at the stage of designing and at the stage of production, storage, transportation, sales and operation [16]-[18].

\section{Results}

We'd like to consider the national and interstate standards, related to the pipe products, operating in Russia. The data, represented in Fig. 1, demonstrate fast growth of the number of new standards, which shows profound alterations of technologies, equipment, used materials and pipe products quality performances. On the other part, ensuring the principle of complex standardization, all new standards, adopted in the period from 2010 to 2019, definitely have reference to the previously adopted standards.

For example, the interstate standard GOST 31447-2012 "Welded Steel Pipes for Main Gas Pipelines, Oil Pipelines, Oil Product Pipelines. Specifications" is prepared on the basis of the national standard of the Russian Federation GOST R 52079-2003, and came into force on 1 January 2015. The new standard has regulatory references to 60 other standards, regulating factors, which determined the finished product quality. Herewith, initially, the new standard, adopted in 2012 and came into force in 2015, contains references, and, consequently, contains requirements, adopted significantly earlier, staring from 1975 [19]- [21]. The image of references in the international standards is formed up in a similar manner.

We'd like to consider the main directions of interconnection of the requirements of standards, related to pipe products, at the example of the standard GOST 32528-2013 "Seamless Hot Finished Steel Pipes. Specifications", adopted for the first time in 2013 and brought into force on 1 January 2016. The standard is applied to the conventional hot finished seamless pipes from carbon and alloy steel for the pipelines, structures, vehicle parts and other technical purposes. The references to 56 standards, related to the issues of metrology and measurements, and metallurgy as well, are provided in the standard. "The reference tree", which forms the interconnection of references for GOST 325282013 is represented in Fig. 3. 


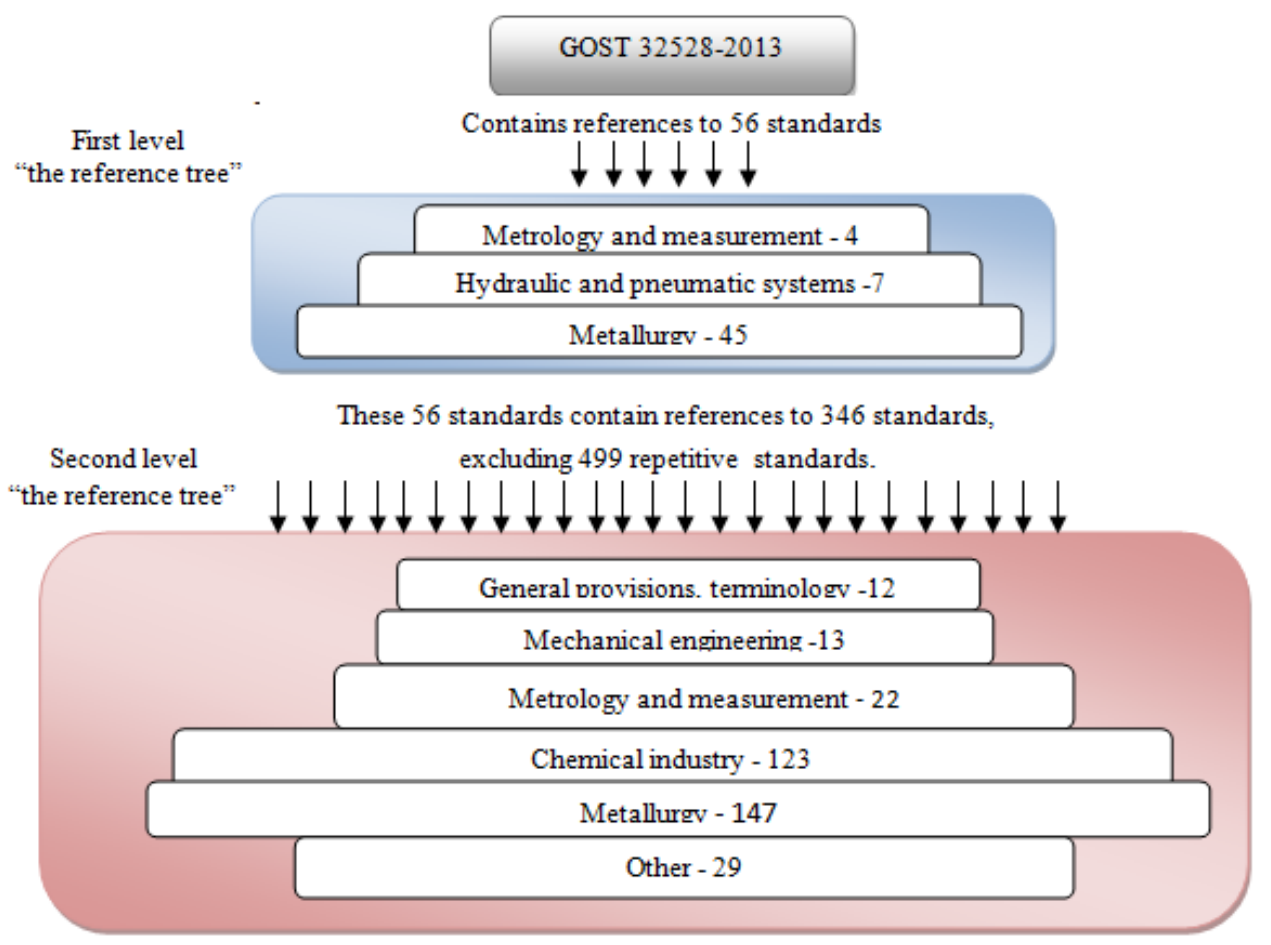

Fig. 3 Conceptual diagram of formation "the reference tree" complex standardization

In compliance with the All-Russian Classification for Standards (ARCS), which represents the complete genuine text of the International Classification for Standards ISO/INFKO ICS, the references were forwarded to the following classification sections:

Section 17 - Metrology and Measurements. Physic Phenomena -4 standards.
Section 23 - Hydraulic and Pneumatic Systems, and General Purpose Components - 7 standards.

Section 77 - Metallurgy - 45 standards.

The detailed information on the subject matter of the standards, to which the regulatory references are provided at the first level of "the reference tree" in the standard GOST 32528-2013, is represented in the Table.

Table. The subject of standards at the first level of "the reference tree"

\begin{tabular}{|c|c|c|c|}
\hline \multicolumn{3}{|c|}{$\begin{array}{l}\text { Classification of standards in accordance with the all-Russian classifier OK 001-2000 } \\
\text { (corresponds to the international classification MK 001-96) }\end{array}$} & \multirow[t]{2}{*}{$\begin{array}{c}\text { Number of } \\
\text { standards }\end{array}$} \\
\hline Section & Group & Subgroup & \\
\hline $\begin{array}{l}17 \text { Metrology and measurement. } \\
\text { Physical phenomena }\end{array}$ & $\begin{array}{l}\text { 17.040 Linear and } \\
\text { Angle Measurements }\end{array}$ & $\begin{array}{c}17.040 .30 \\
\text { Measuring instruments }\end{array}$ & 4 \\
\hline $\begin{array}{l}23 \text { Hydraulic and pneumatic } \\
\text { systems and general components }\end{array}$ & $\begin{array}{l}23.040 \text { Pipelines and } \\
\text { their components }\end{array}$ & $\begin{array}{c}23.040 .10 \\
\text { Cast iron and steel pipes }\end{array}$ & 7 \\
\hline \multirow{9}{*}{$\begin{array}{l}77 \\
\text { Metallurgy }\end{array}$} & \multirow[b]{2}{*}{77.040 Metal testing } & 77.040.10 Mechanical testing of metals & 3 \\
\hline & & 77.040 .30 Chemical analysis of metals & 1 \\
\hline & \multirow[b]{2}{*}{ 77.080 Ferrous metals } & 77.080 .01 Ferrous metals in general & 13 \\
\hline & & 77.080.20 Steel & 23 \\
\hline & \multirow[b]{4}{*}{$\begin{array}{l}77.140 \\
\text { Iron and steel products }\end{array}$} & $\begin{array}{l}\text { 77.140.01 Iron and steel products in } \\
\text { general }\end{array}$ & 1 \\
\hline & & $\begin{array}{c}77.140 .40 \text { Steel with special magnetic } \\
\text { properties }\end{array}$ & 1 \\
\hline & & 77.140.45 Unalloyed steels & 2 \\
\hline & & $\begin{array}{l}\text { 77.140.50 Steel sheet products and semi- } \\
\text { finished products }\end{array}$ & 1 \\
\hline & \multicolumn{2}{|l|}{ Total } & 56 \\
\hline
\end{tabular}


In GOST 32528-2013, the main references are referred to the following groups: ferrous metals, tests of metals, and linear and angular measurements.

At the second level of "the reference tree", ensuring complex standardization, the references to even 845 standards are provided. After exclusion of repeated standards, 346 standards, referred to different ARCS sections, remain: metallurgy, chemical industry, metrology and measurements, and others. In Fig. 4, the distribution of references over ARCS sections for the first and second levels of "the reference tree" is demonstrated on a percentage basis.
According to this diagram, we can state, that the most important parameters, forming pipe product quality performances, for the standards, related to the pipe products, is the data, represented in the following sections: metallurgy, chemical industry, metrology and measurements.

Then, we'd like to consider, in what way are the references distributed by time frames of their adoption. The distribution of standards, provided in the section "Regulatory References" of GOST 32528-2013 by the time of their adoption, is represented in Fig. 5.

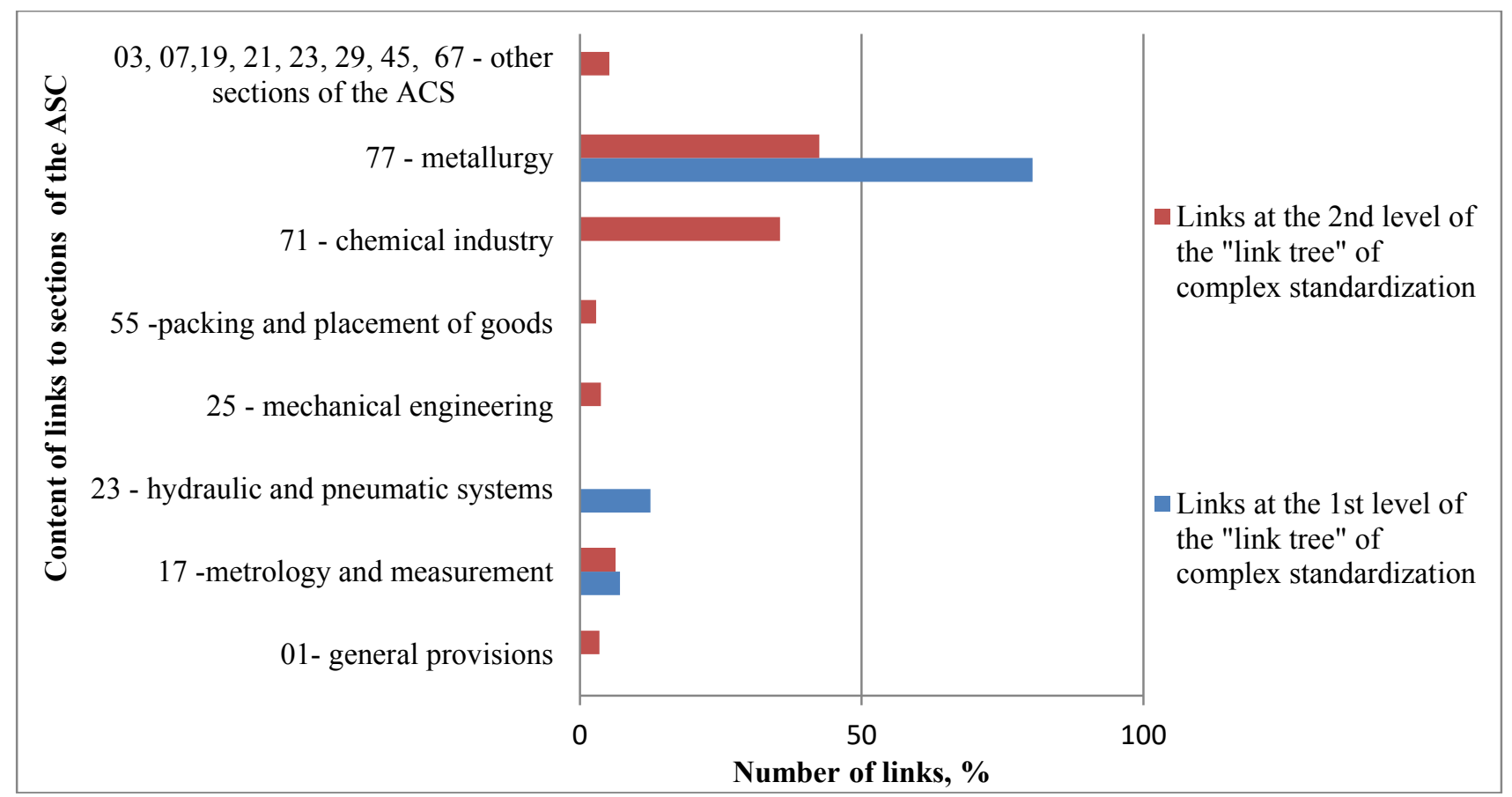

Fig. 4 Distribution of references as a percentage of the number at the first and second levels of "the reference tree" of complex standardization by sections of the ACS

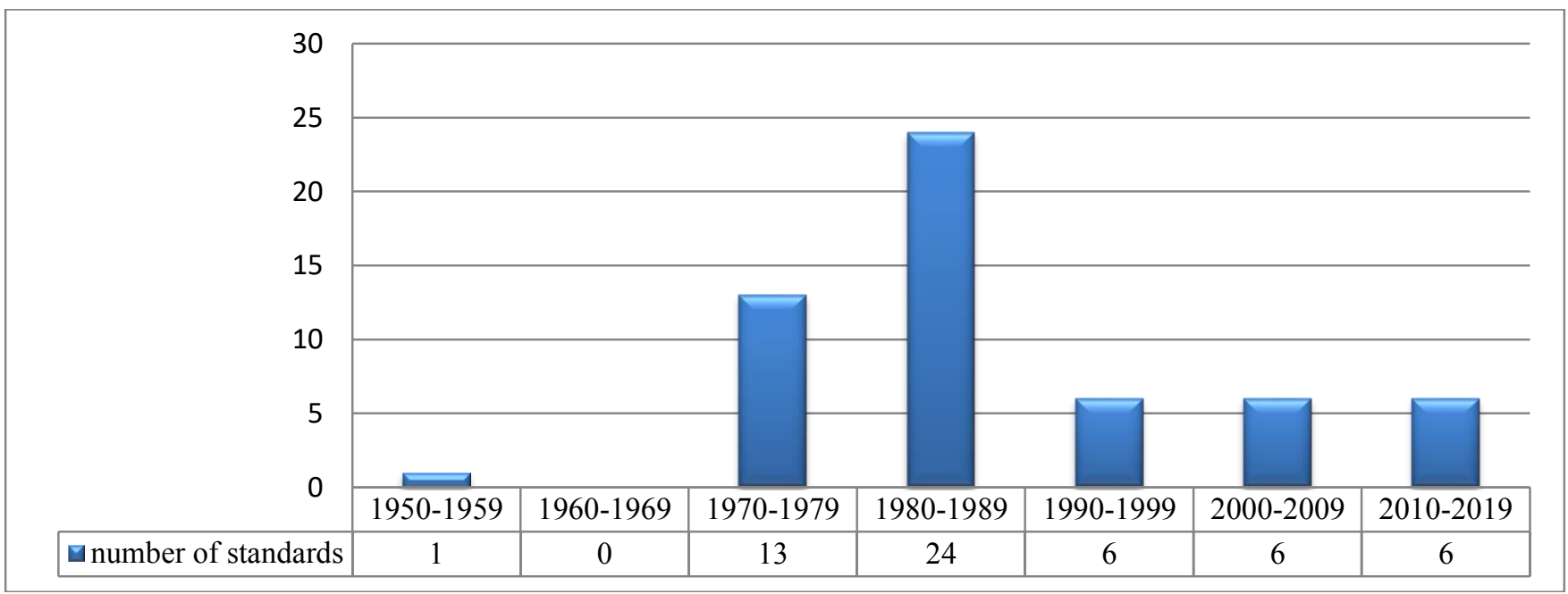

Fig. 5 Distribution of the standards given in the section "Normative references" GOST 32528-2013 by the date of adoption 
The largest number of references is referred to the standards, adopted in 1980-1989, then the period from 1970 to 1979 is observed, and only afterwards the references are given to the standards, adopted after the year 2000 .

Considered 56 standard at the second level of "the reference tree", in their turn, have references to
845 standards, and after the exclusion of repeats, remain 346 standards, to which the references are contained. The distribution of these 346 standards by the date of their adoption is provided in Fig. 6 .

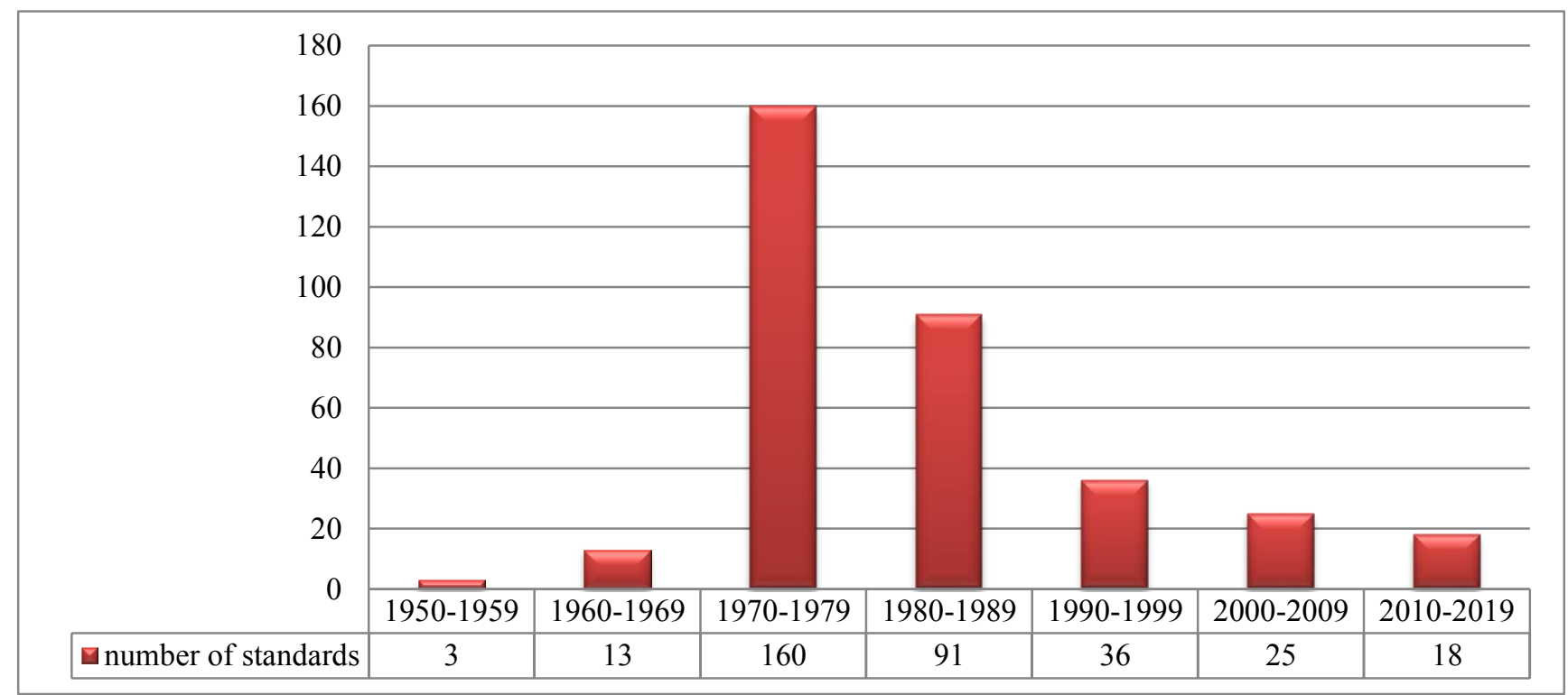

Fig. 6 Distribution of standards given in the section "Normative references" 56 standards, which are referenced in GOST 32528-2013 by the date of adoption

Both provided figures demonstrate the handling through regulatory references to the standards, adopted, mainly, 40-50 years ago. Besides, the major amount of the references is moved back to the past by 10 years at the second level of "the reference tree": the major amount of references is referred to the standards, adopted in 1970-1979, then the standards, adopted in 1980-1989 and 1990-1999 are provided, and only afterwards the referencing to the standards, adopted after 2000, is observed.

The identified patterns of the standards system for pipe products represent a typical situation for any type of product. Differences may be in the number of standards, but qualitatively the picture is characteristic of any type of product, as the necessity to ensure links between standards is due to the adopted standardization system in Russia [14]. Thus, during the development of national, regional, and international standards as well, a quite complicate situation takes place, when new standards of the recent decade refer to the data, established, mainly, 50 years ago. It is impossible to

cancel these relations without the destruction of complete standardization system, consequently, it is required to create special relations between the standards of the $1^{\text {st }}, 2^{\text {nd }}, \mathrm{n}^{\text {th }}$ levels of "the reference three" through new availabilities of modern information systems.

As of today, the relations between the standards are exclusively sequential, and up and down, in the result of which the duplication of the documents, aimed to reservation of all related requirements, occurs. This system severeness and onedimensionality ensure high authenticity of information, and effectively work in case of nonsignificant alterations, made simultaneously in the regulatory documents. However, under the conditions of implementation of new technologies, including the digital ones, when the compulsory provision of management is the reduction of time of response to parameter alterations within the frames of operating and future systems of decision-making, it is required to ensure the system speed-of-response along with the assurance of information authenticity and requirement interconnection.

\section{Conclusions}

The interconnection and coordination of the requirements to product quality and safety is ensured by means of complex standardization.

The mechanism of complex standardization, operated through the forming-up of "the reference tree" of the first and second levels, has been traced at 
the example of requirements to pipe products, GOST 32528-2013.

The distribution of regulatory references at the first and second levels of "the reference tree" demonstrate, that during the development of a new standard, the referencing to the standards, adopted, mainly, 40-50 years ago, takes place. Herewith, the major amount of the references at the second level of "the references tree" moves back by 10 years more. Thus, the new standards of the recent decade refer to the data, determined 40-50 years ago, which may retard the forming-up of requirements to the quality of products through the application of measurement means, test and monitoring methods, and used primary products.

At a new standard implementation, for the purposes of assurance of interconnected requirements, it is required to update the requirements, ensuring systematization, optimization, and concurrence of all cooperating factors, influencing the specific object of standardization and ensuring economically preferable level of the object quality, in an integrated manner. It is required the development of special relations between the standards of the $1^{\text {st }}, 2^{\text {nd }}, n^{\text {th }}$ levels of "the reference three" through new availabilities of modern information systems.

\section{References:}

[1] Y. Liao, S. Deschamps, E.F.R. Loures, L.F.P. Ramos, Past, present and future of Industry 4.0 -a systematic literature review and research agenda proposal, International Journal of Production Research, V. 55, N 12, 2017, pp. 3609-3629

[2] M.A. Shneps-Shneppe, S.P. Seleznev, D.E. Namiot, V.P. Kupriyanovskyi, About cybersecurity of state critical infrastructure, International Journal of Open Information Technologies, Vol.4, No. 7, 2016, pp.1731

[3] V.P. Kupriyanovskyi, S.A. Sinyago, A.P. Dobrynin, BIM-Digital Economy. How did you achieve success? A practical approach to the theoretical concept. Part 1. Approaches and Key Benefits, International Journal of Open Information Technologies, Vol.4, No. 3, 2016, pp.1-8.

[4] M. Ghobakhloo, The future of manufacturing industry: a strategic roadmap toward Industry 4.0, Manufacturing Technology Management, Vol. 29, No 6, 2018. pp. 910-396

[5] A.V. Zazhigalkin, Standartization - Methodology and Practice, Moscow: RIA "Standards and Quality", 2017, pp. 89

[6] V.Ya. Belobragin, A.V. Zazhigalkin, T.I. Zvorykina, Basics of Standardization, Moscow: RIA "Standards and Quality", 2017, pp. 516
[7] A.V. Zazhigalkin, The goals and tasks of standardization for 2016, Standars and Quality, No 3, 2016.

[8] The Economics of Standardization: an update G.M. Peter Swann. Innovative Economics Limited Report for the UK Department of Business. Innovation and Skills (BIS) Complete Draft Version 2.2 - Innovative Economics Limited, 2010

[9] The Economic Contribution of Standards to the UK Economy June 2015 CERB

[10] S. Weyer, M. Shmitt, M. Ohmer, D. Goreck, Towards Industry 4.0 - Standardization as the crucial challenge for highly modular, multi-vendor production systems, IFAC PapersOnLine, Vol. 48, No 3, 2015, pp. 579-584

[11] S. Choi, C. Jung, B. Kulvatunyou, K.C. Mossis. An analysis of technologies and standards for designing smart manufacturing systems, Journal of Research of the National Institute of Standards and Technology, Vol.121, 2016, pp. 422-433

[12] V. Kupriyanovsky, D. Yartsev, N. Utkin, D. Namiot. Economy standards in the digital age and information and communication technologies on the example of the British Standards Institute, International Journal of Open Information Technologies, Vol.4, No 6, 2016, pp. 1-9

[13] N. Kazantseva, G. Tkachuk, T. Kazantseva, Standardization in the Era of Information and Digital Revolution: a View from the Provinces, Standards and Quality, No 2, 2020, pp. 30-34

[14] N.K. Kazantseva, G.A. Tkachuk, T.V. Kazantseva, What Needs to be Changed in a Standards Management System, Standards and Quality, No 6, 2020, pp.14-18

[15] V.P. Shvandar, V.P. Panov, E.M. Kupryakov and others. Standardization and Quality Management. Moscow: UNITY DANA. 2001, pp. 487

[16] B.Yu. Brod, G.P. Bunin, Development of standardization methodology as a science, Standards and Quality, 2012, No 2, pp.56-58.

[17] Dr. S. Prasanna, Dr. N. Manikandan, Dr. K. Vijayakumar and Dr. Anusha K, Survey of Block Chain Technology for Digitization in India, International Journal of Civil Engineering and Technology, 9(6), 2018, pp. $750-756$.

[18] Marcin Kotarba, Measuring digitalization Key Metrics Foundations of Management, Vol. 9 (2017), pp. $123-138$

[19] N.K. Kazantseva, G.A. Tkachuk, A.L. Nevolina, V.S. Shavrin, The Problems of Standards Clssification, International Journal of Management (IJM), Volume 11, Issue 3, March 2020, pp. 36-42

[20] A. Zazhigalkin, V. Pugachev, A. Petrosyan, The Digital Economy and Stadardization Future, Standards and Quality. 2017, No 9, pp. 30-34.

[21] A. Zazhigalkin, V. Pugachev, A. Petrosyan, The Digital Economy and Stadardization Future, Standards and Quality, 2017, No 10, pp .23-27 
Contribution of individual authors to the creation of a scientific article (ghostwriting policy)

T.V. Kazantseva, N.K. Kazantseva, G.A. Tkachuk were responsible for analyzing the processed data

V.S. Kukhar, A. L. Nevolina processed the data.

N.A. Baganov, V.A. Aleksandrov have collected the data.

\section{Creative Commons Attribution License 4.0} (Attribution 4.0 International, CC BY 4.0)

This article is published under the terms of the Creative Commons Attribution License 4.0

https://creativecommons.org/licenses/by/4.0/deed.en US 